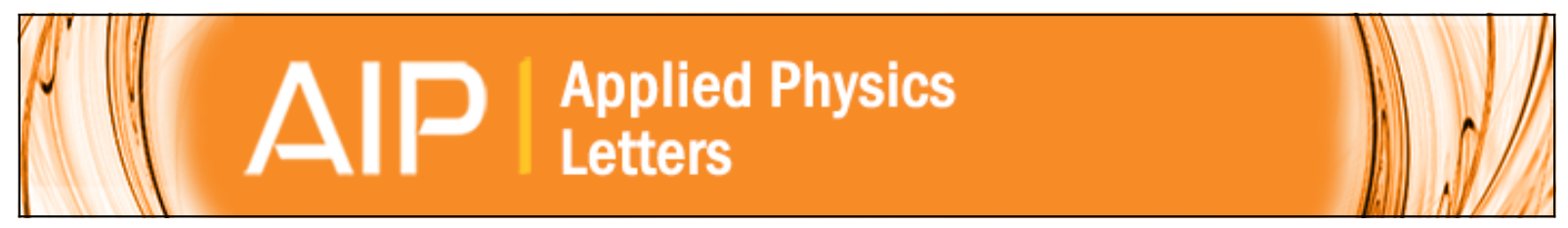

\title{
Atomic transport across the interfaces during the formation of ultrathin silicon oxide/nitride/oxide films
}

I. J. R. Baumvol, T. D. M. Salgado, C. Radtke, C. Krug, and J. de Andrade

Citation: Applied Physics Letters 73, 1970 (1998); doi: 10.1063/1.122338

View online: http://dx.doi.org/10.1063/1.122338

View Table of Contents: http://scitation.aip.org/content/aip/journal/apl/73/14?ver=pdfcov

Published by the AIP Publishing

\section{Articles you may be interested in}

Inhibition of excess interface $\mathrm{Si}$ atom generation in $700^{\circ} \mathrm{C}$-grown pyrolytic-gas passivated ultrathin silicon oxide films

J. Vac. Sci. Technol. A 23, 599 (2005); 10.1116/1.1924580

Interface formation during the yttrium oxide deposition on Si by pulsed liquid-injection plasma enhanced metalorganic chemical vapor deposition

J. Vac. Sci. Technol. A 22, 2490 (2004); 10.1116/1.1810163

Effect of nitrogen containing plasmas on interface stability of hafnium oxide ultrathin films on $\mathrm{Si}$ ( 100 )

Appl. Phys. Lett. 85, 1574 (2004); 10.1063/1.1785856

Interfacial silicon oxide formation during oxygen annealing of Ta 2 O 5 thin films on Si: Oxygen isotope labeling J. Vac. Sci. Technol. A 18, 2522 (2000); 10.1116/1.1286717

Reaction/annealing pathways for forming ultrathin silicon nitride films for composite oxide-nitride gate dielectrics with nitrided crystalline silicon-dielectric interfaces for application in advanced complementary metal-oxide-semiconductor devices

J. Vac. Sci. Technol. A 17, 1340 (1999); 10.1116/1.581818

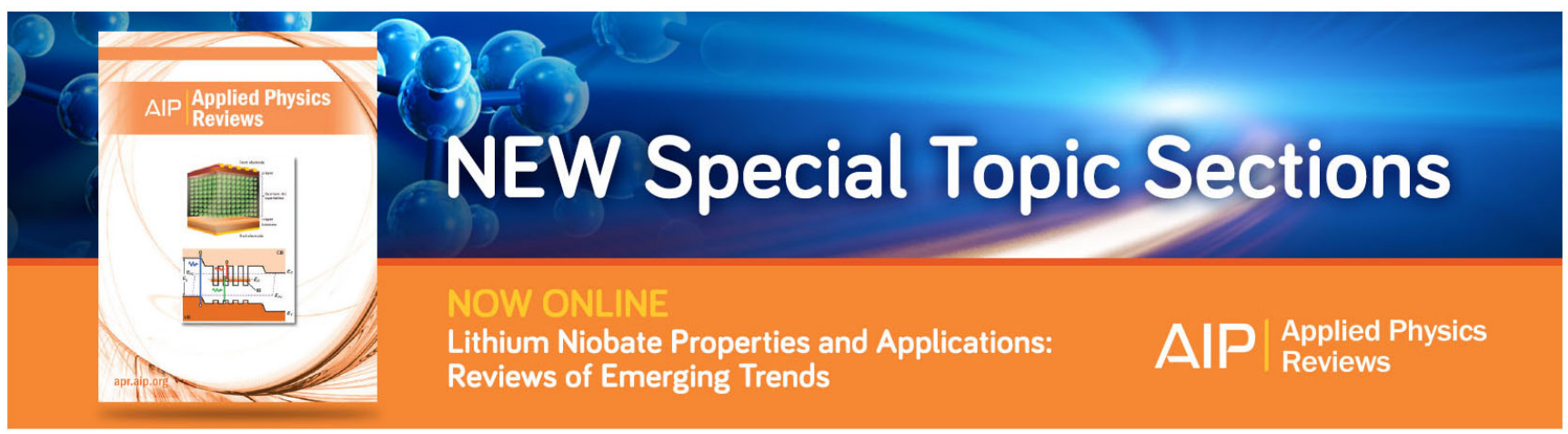




\title{
Atomic transport across the interfaces during the formation of ultrathin silicon oxide/nitride/oxide films
}

\author{
I. J. R. Baumvola) \\ Instituto de Física, Universidade Federal do Rio Grande do Sul, 9500-Porto Alegre-RS, Brazil, 91509-900 \\ T. D. M. Salgado, C. Radtke, C. Krug, and J. de Andrade \\ Instituto de Química, Universidade Federal do Rio Grande do Sul, 9500-Porto Alegre-RS, \\ Brazil, 91509-900
}

(Received 13 July 1998; accepted for publication 5 August 1998)

\begin{abstract}
The redistribution of $\mathrm{O}$ and $\mathrm{N}$ during the final, thermal oxidation in dry $\mathrm{O}_{2}$ step in the formation of ultrathin silicon oxide/nitride/oxide dielectric films (ONO) was investigated using isotopic tracing and depth profiling with nanometer resolution. The results show that the final oxidation step induces atomic transport of $\mathrm{O}$ and $\mathrm{N}$ species in the system, such that the formed ONO structures are not stacked layer structures, but rather a silicon oxynitride ultrathin film, having moderate concentrations of $\mathrm{N}$ in the near-surface and near-interface regions, and a high $\mathrm{N}$ concentration in the bulk. (c) 1998 American Institute of Physics. [S0003-6951(98)04040-6]
\end{abstract}

The increase of the packing density of dynamic-randomaccess memories (DRAM) requires ultrathin dielectric films with low leakage current and high reliability. ${ }^{1-6}$ Ultrathin structures of silicon oxide/nitride/oxide on silicon (ONO) are able to fulfill these requirements, as they reduce hot carrier damage and suppress boron penetration. The usual routine to prepare ultrathin ONO films ${ }^{7}$ consists of the thermal growth of a $\mathrm{SiO}_{2}$ film $(2-5 \mathrm{~nm})$ on $\mathrm{Si}$ in dry oxygen (bottom oxide), followed by the deposition of a $\mathrm{Si}_{3} \mathrm{~N}_{4}$ film (also $2-5 \mathrm{~nm}$ ) by one of the many available versions of chemical vapor deposition (CVD), and finally, a reoxidation in wet or dry oxygen (top oxide). Many authors have ascribed the reliability of ONO structures to the sum of the advantageous characteristics of each "layer.' Hönlein and Reisinger, ${ }^{7}$ for instance, discussed the importance of each one of the components of a ONO stacked structure. According to them: (i) the bottom oxide maintains the good quality of the $\mathrm{Si} / \mathrm{SiO}_{2}$ interface, (ii) the nitride layer increases the dielectric constant of the film, and is a diffusion barrier to boron and other doping elements, and (iii) the top oxide seals weak spots in the $\mathrm{Si}_{3} \mathrm{~N}_{4}$ and is necessary when the gate dielectric is used under symmetric electrical conditions. These and other authors ${ }^{8-11}$ neglected the improvements that can be obtained due to the "interaction' of the three layers composing the ONO structure. In fact, the strictly stacked nature of the ONO structures prepared as described above is questionable in the case of ultrathin films: even extremely thin top oxide layers of approximately $1 \mathrm{~nm}$ prevent electron and hole currents very effectively, something that cannot be explained by a simple model of a $1 \mathrm{~nm}$ top oxide with a sharp boundary with the nitride layer. The final step of thermal oxidation most probably produces a graded transition between $\mathrm{SiO}_{2}$ and $\mathrm{Si}_{3} \mathrm{~N}_{4}$. This was observed by different authors ${ }^{12-14}$ who studied the impact of rapid thermal processing in the final oxidation step, on the electrical properties of the film. For instance, the interface charge density was found to be reduced in all three

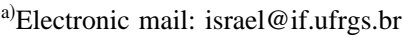

interfaces. Furthermore, it was shown that a thermal oxidation that promotes the redistribution of the chemical species reduces interface stresses. Finally, the existence of a superficial oxynitride layer was observed, although using profiling methods which did not have the required depth resolution.

We used isotopic tracing and high-resolution depth profiling techniques to achieve a better understanding of the effect of the final oxidation step on the distribution of the chemical species present in ONO structures. The starting structure had a bottom oxide $\left(\mathrm{Si}^{16} \mathrm{O}_{2}\right)$ thermally grown on $\mathrm{Si}(100)$ in dry ${ }^{16} \mathrm{O}_{2}$ at $1000{ }^{\circ} \mathrm{C}$ in a rapid thermal processing furnace. The nitride layer $\left(\mathrm{Si}_{3}{ }^{15} \mathrm{~N}_{4}\right)$ was deposited by remote plasma enhanced chemical vapor deposition in a mixture of ${ }^{15} \mathrm{~N}_{2}$ and silane. The depth profile of ${ }^{16} \mathrm{O}$ in these starting samples was determined using step-by-step chemical etching ${ }^{15}$ in a HF solution. Figure 1(a) shows the areal density of ${ }^{16} \mathrm{O}$ after each step of chemical etching as a function of the areal densities of ${ }^{15} \mathrm{~N}+{ }^{16} \mathrm{O}$; the ${ }^{16} \mathrm{O}$ depth profile shown in the inset was obtained by differentiation of this curve, and the depth resolution is approximately $0.5 \mathrm{~nm}$. The areal density of ${ }^{16} \mathrm{O}$ was determined using the ${ }^{16} \mathrm{O}\left(d, p_{0}\right){ }^{17} \mathrm{O}$ nuclear reaction, ${ }^{15}$ in the plateau region of the cross section around $810 \mathrm{keV}$, calibrated against a $\mathrm{Ta}_{2} \mathrm{O}_{5}$ film standard containing $5.7 \times 10^{17}{ }^{16} \mathrm{O} \mathrm{cm}^{-2}$. The areal density of ${ }^{15} \mathrm{~N}$ was determined by nuclear reaction analysis (NRA), using a plateau region of the cross sections of the ${ }^{15} \mathrm{~N}(p, \alpha \gamma){ }^{12} \mathrm{C}$ reaction at $730 \mathrm{keV}$, and a convenient standard. ${ }^{15}$ The ${ }^{15} \mathrm{~N}$ profile was determined by nuclear resonance profiling (NRP), ${ }^{16}$ using the narrow and isolated resonance in the cross section of the ${ }^{15} \mathrm{~N}(p, \alpha \gamma){ }^{12} \mathrm{C}$ nuclear reaction at $429 \mathrm{keV}\left(\Gamma_{R}\right.$ $=120 \mathrm{eV})$, and a tilted sample geometry $\left(\psi=65^{\circ}\right)$. The measured excitation curve (i.e., gamma yield versus incident proton energy) around the resonance energy is shown in Fig. 1(b); it was converted into ${ }^{15} \mathrm{~N}$ concentration versus depth (shown in the inset) by means of the SPACES simulation program. ${ }^{17}$ The depth resolution is approximately $0.7 \mathrm{~nm}$ near the surface. One notices from Fig. 1 an abrupt interface between the nitride and the bottom oxide. The areal densities can be converted into thicknesses by the approximate rela- 


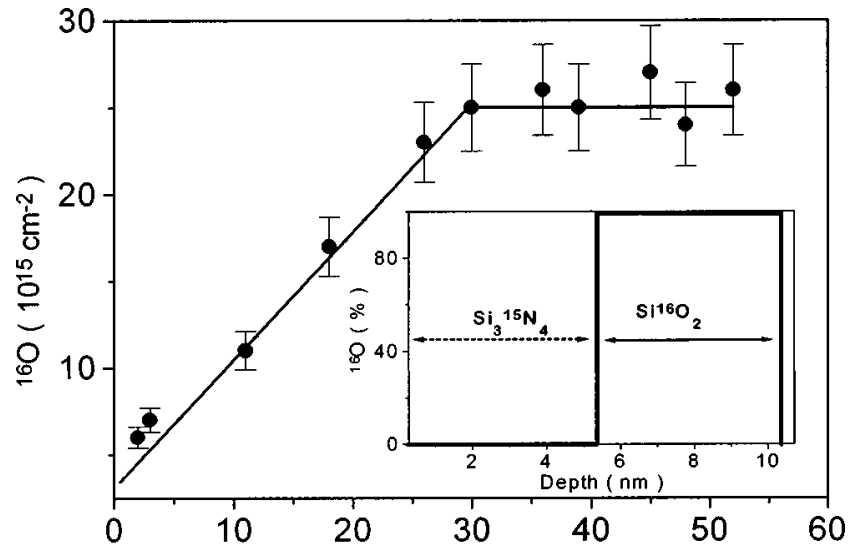

(a)

$16 \mathrm{O}+15 \mathrm{~N}\left(10^{15} \mathrm{~cm}^{-2}\right)$

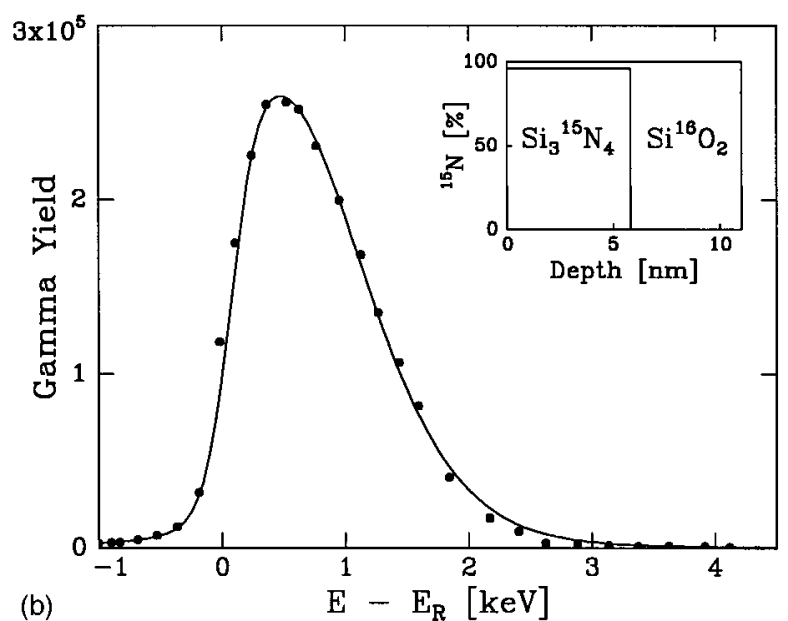

FIG. 1. (a) Areal density of ${ }^{16} \mathrm{O}$ after each step of chemical etching as a function of the areal densities of ${ }^{16} \mathrm{O}+{ }^{15} \mathrm{~N}$ in the starting $\mathrm{Si}^{16} \mathrm{O}_{2}+\mathrm{Si}_{3}{ }^{15} \mathrm{~N}_{4}$ structure. The ${ }^{16} \mathrm{O}$ profile obtained by differentiation of this curve is shown in the inset; (b) excitation curve around the resonance energy at $429 \mathrm{keV}$ of the ${ }^{15} \mathrm{~N}(p, \alpha \gamma){ }^{12} \mathrm{O}$ nuclear reaction, and the corresponding ${ }^{15} \mathrm{~N}$ profile in the inset for the same sample as in (a).

tionships: $1 \times 10^{15} \mathrm{O} \mathrm{cm}^{-2}=0.226 \mathrm{~nm}$ of $\mathrm{SiO}_{2}$, and 1 $\times 10^{15} \mathrm{~N} \mathrm{~cm}^{-2}=0.188 \mathrm{~nm}$ of $\mathrm{Si}_{3} \mathrm{~N}_{4}$.

The starting samples underwent a further oxidation step in a Joule-effect heated furnace, in 50 mbar of dry, 97\% ${ }^{18} \mathrm{O}_{2}$-enriched $\mathrm{O}_{2}$ at temperatures between 900 and $1000{ }^{\circ} \mathrm{C}$ for $60 \mathrm{~min}$. The ${ }^{18} \mathrm{O}$ profiles were then determined by NRP using the resonance in the ${ }^{18} \mathrm{O}(p, \alpha){ }^{15} \mathrm{~N}$ nuclear reaction at $151 \mathrm{keV} .{ }^{16}$ The corresponding excitation curves and ${ }^{18} \mathrm{O}$ depth profiles are shown in Fig. 2(a), showing that the ${ }^{18} \mathrm{O}$ content increases with the oxidation temperature. The areal densities of ${ }^{18} \mathrm{O}$ in each sample were also determined by NRA. ${ }^{15}$ According to the measured ${ }^{18} \mathrm{O}$ areal densities, stacked layer structures would show top oxides with thickness in the range from 1.5 to $2.5 \mathrm{~nm}$, containing ${ }^{18} \mathrm{O}$ in concentrations equal to $97 \%$ (the isotopic labeling of the enriched gas). However, the ${ }^{18} \mathrm{O}$ profiles of Fig. 2(a) reveal that the concentration of this isotope is always much smaller than $97 \%$, and that ${ }^{18} \mathrm{O}$ is incorporated at depths appreciably beyond $2.5 \mathrm{~nm}$, its concentration decreasing with increasing depth.

The ${ }^{15} \mathrm{~N}$ profiles for the oxidized samples shown in Fig. 2(b) indicate a noticeable redistribution and loss of this species, which increase with processing temperature. A com-
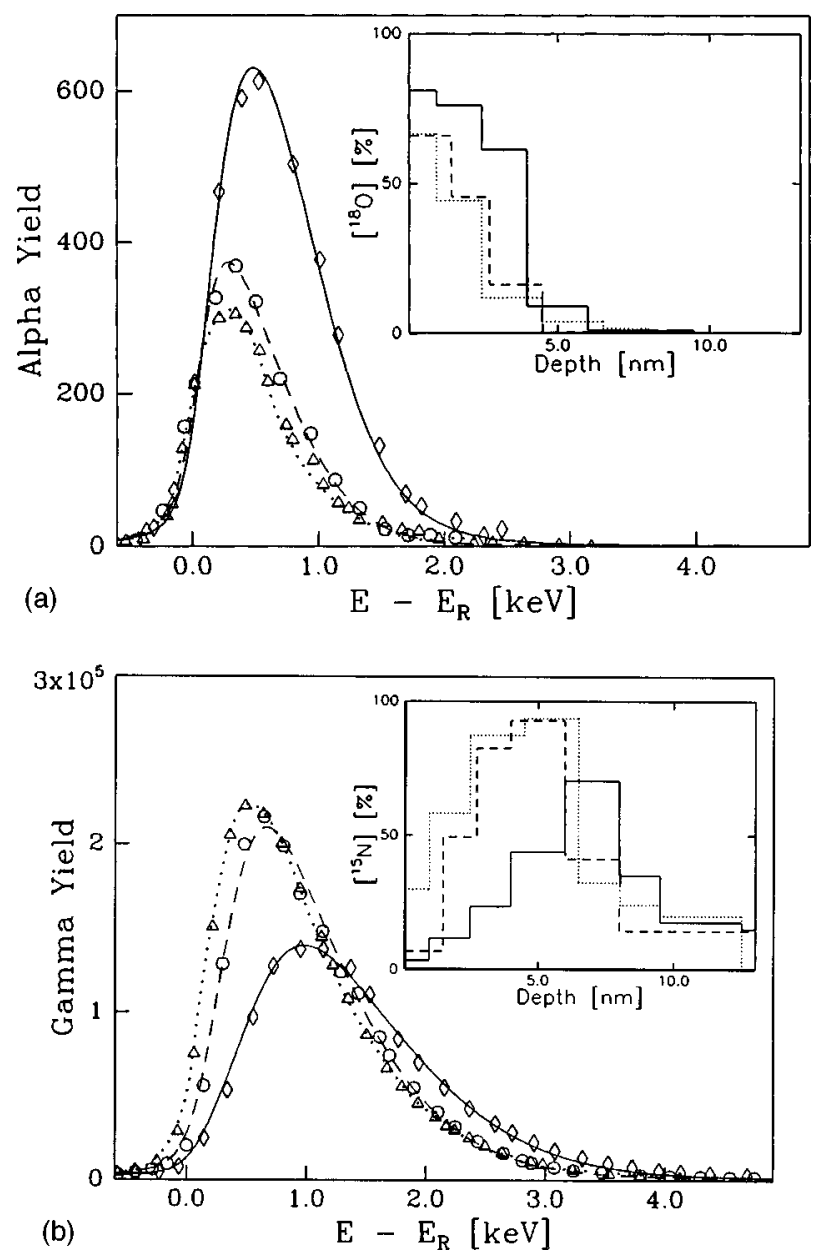

FIG. 2. (a) Excitation curves of the ${ }^{18} \mathrm{O}(p, \alpha){ }^{15} \mathrm{~N}$ nuclear reaction around the resonance at $151 \mathrm{keV}$, and the corresponding ${ }^{18} \mathrm{O}$ profiles in the insets, for the samples oxidized in ${ }^{18} \mathrm{O}_{2}$ at 900 (triangle, dot line), 950 (circle, dashed line), and $1000{ }^{\circ} \mathrm{C}$ (diamond, solid line) for $60 \mathrm{~min}$; (b) ${ }^{15} \mathrm{~N}$ excitation curves and depth profiles for the same samples (same corresponding symbols) as in (a).

parison of these ${ }^{15} \mathrm{~N}$ profiles with that corresponding to the starting $\mathrm{Si}^{16} \mathrm{O}_{2}+\mathrm{Si}_{3}{ }^{15} \mathrm{~N}_{4}$ structure (Fig. 1) indicates that ${ }^{15} \mathrm{~N}$ migrates into the bottom oxide $\left(\mathrm{Si}^{16} \mathrm{O}_{2}\right)$, eventually reaching the $\mathrm{ONO} / \mathrm{Si}$ interface, and has a marked depletion of its concentration near the surface.

The overall thicknesses of the so-formed ONO structures did not significantly vary with respect to the starting struc-

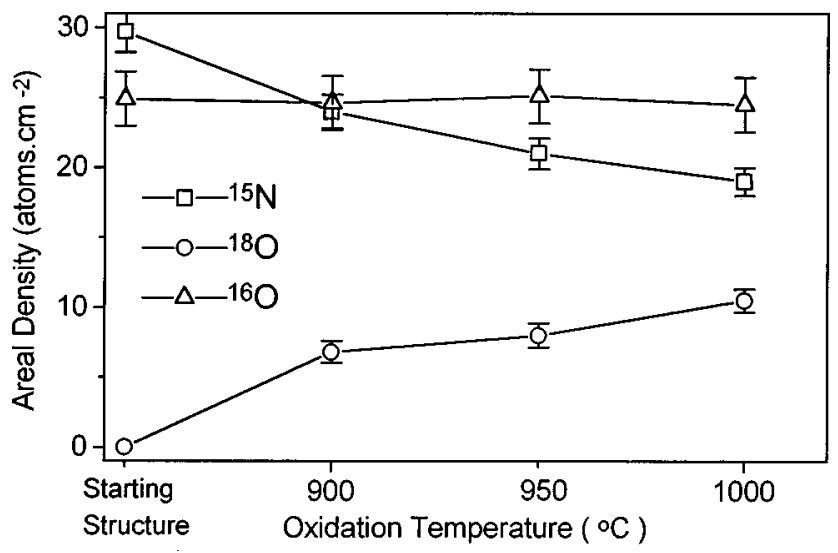

FIG. $3{ }^{15} \mathrm{~N},{ }^{18} \mathrm{O}$, and ${ }^{16} \mathrm{O}$ areal densities at the different oxidation temperatures, as determined by nuclear reaction analysis. 


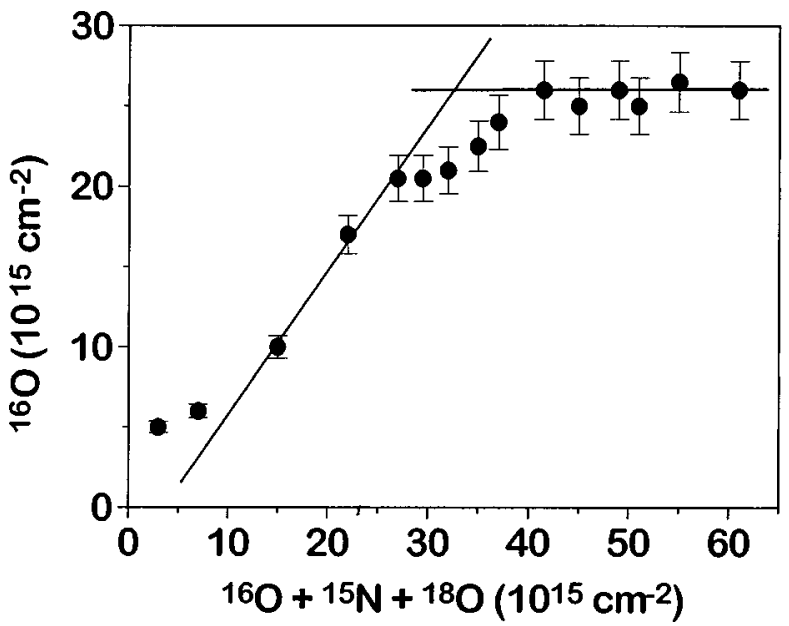

FIG. 4. ${ }^{16} \mathrm{O}$ areal density as a function of the areal densities of ${ }^{16} \mathrm{O}+{ }^{15} \mathrm{~N}+{ }^{18} \mathrm{O}$ after successive steps of chemical etching, for the sample oxidized in ${ }^{18} \mathrm{O}_{2}$ at $950{ }^{\circ} \mathrm{C}$ for $60 \mathrm{~min}$. The solid lines represent the results obtained for the starting $\mathrm{Si}^{16} \mathrm{O}_{2}+\mathrm{Si}_{3}{ }^{15} \mathrm{~N}_{4}$ structure, before thermal oxidation in ${ }^{18} \mathrm{O}_{2}$.

ture after the final oxidation step. Indeed, Fig. 3 shows the ${ }^{15} \mathrm{~N},{ }^{18} \mathrm{O}$, and ${ }^{16} \mathrm{O}$ areal densities as a function of the oxidation temperature, as measured by NRA, indicating that ${ }^{15} \mathrm{~N}$ is lost in comparable amounts to those of incorporated ${ }^{18} \mathrm{O}$, whereas ${ }^{16} \mathrm{O}$ remains constant.

The ${ }^{16} \mathrm{O}$ areal density as a function of the areal densities of ${ }^{16} \mathrm{O}+{ }^{15} \mathrm{~N}+{ }^{18} \mathrm{O}$ after successive steps of chemical etching, for the sample oxidized in ${ }^{18} \mathrm{O}_{2}$ at $950{ }^{\circ} \mathrm{C}$ is shown in Fig. 4 . A comparison of the experimental points with those corresponding to the starting sample (represented by the two solid lines in Fig. 4) shows a depletion of ${ }^{16} \mathrm{O}$ at the $\mathrm{Si}^{16} \mathrm{O}_{2}$ side around the previously sharp $\mathrm{Si}^{16} \mathrm{O}_{2} / \mathrm{Si}_{3}{ }^{15} \mathrm{~N}_{4}$ interface, and the appearance of ${ }^{16} \mathrm{O}$ at the $\mathrm{Si}_{3}{ }^{15} \mathrm{~N}_{4}$ side. This means that ${ }^{16} \mathrm{O}$ atoms migrated into the nitride film, although reaching a rather moderate distance from the previous $\mathrm{Si}^{16} \mathrm{O}_{2} / \mathrm{Si}_{3}{ }^{15} \mathrm{~N}_{4}$ interface.

In summary, the final oxidation step in the formation of an ONO structure, which consists of a thermal oxidation in $\mathrm{O}_{2}$ of a stacked silicon nitride-silicon oxide bilayer on
$\mathrm{Si}(100)$, induces atomic transport of the $\mathrm{O}$ and $\mathrm{N}$ species in the system. The incoming oxygen atoms are introduced into the silicon nitride layer, forming silicon oxynitride in the first nanometers from the surface. Concomitantly, $\mathrm{N}$ and $\mathrm{O}$ species already present in the system migrate, such that $\mathrm{N}$ is found redistributed throughout the entire length of the film, reaching the $\mathrm{ONO} / \mathrm{Si}$ interface. Oxygen species from the bottom layer slightly penetrate (approximately $2 \mathrm{~nm}$ ) into the previous silicon nitride layer. The thickness of the ONO film does not significantly vary due to the final oxidation step, as $\mathrm{N}$ is lost by desorption in comparable amounts to those of incorporated O. So, we conclude that the ONO structures formed in the present work are not stacked layer structures, but rather silicon oxynitride ultrathin films, showing moderate concentrations of $\mathrm{N}$ in the near-surface and near-interface regions, and high $\mathrm{N}$ concentration in the bulk.

${ }^{1}$ H. Reisinger and A. Spitzer, J. Appl. Phys. 79, 3028 (1996).

${ }^{2}$ D.-W. Kim, K.-J. Kim, D.-I. Kim, W.-J. Lee, S.-Y. Lee, Y. J. Lee, S.-K. Rha, and C.-O. Park, J. Mater. Sci.: Mater. Electron. 8, 91 (1997).

${ }^{3}$ H.-W. Liu, H.-P. Su, and H.-C. Cheng, Jpn. J. Appl. Phys., Part 1 34, 1713 (1995)

${ }^{4}$ N. Matsuo and A. Sasaki, Solid-State Electron. 39, 337 (1996).

${ }^{5}$ N. Matsuo, H. Fujiwara, T. Miyoshi, and T. Koyanagi, IEEE Electron Device Lett. 17, 56 (1996).

${ }^{6}$ Y.-C. Shih, G. Zhang, C. Hu, and W. G. Oldham, Appl. Phys. Lett. 67, 2040 (1995).

${ }^{7}$ W. Hönlein and H. Reisinger, Appl. Surf. Sci. 39, 178 (1989).

${ }^{8}$ R. Kies, G. Ghibaudo, G. Pananakakis, O. Roux-dit-Buison, and G. Reimbold, Microelectron. Eng. 28, 310 (1995).

${ }^{9}$ A. Spitzer and R. Baunach, Appl. Surf. Sci. 39, 192 (1989).

${ }^{10}$ Z. A. Weinberg, K. J. Stein, T. N. Nguyen, and J. Y. Sun, Appl. Phys. Lett. 57, 1248 (1990).

${ }^{11}$ S. V. Hattangady, G. G. Fountain, R. G. Alley, R. A. Ruder, and R. J. Markunas, J. Vac. Sci. Technol. A 9, 1094 (1991).

${ }^{12}$ Y. Ma, T. Yasuda, and G. Luckovsky, J. Vac. Sci. Technol. B 11, 1533 (1993).

${ }^{13}$ W. T. Chang, D. K. Shih, D. L. Kwong, Y. Zhou, and S. Lee, Appl. Phys. Lett. 54, 430 (1989).

${ }^{14}$ W. Ting, S. N. Lin, and D. L. Kwong, Appl. Phys. Lett. 55, 2313 (1989).

${ }^{15}$ I. J. R. Baumvol, F. C. Stedile, J.-J. Ganem, S. Rigo, and I. Trimaille, J. Electrochem. Soc. 142, 1205 (1995).

${ }^{16}$ I. J. R. Baumvol, F. C. Stedile, J.-J. Ganem, S. Rigo, and I. Trimaille, J. Electrochem. Soc. 143, 2938 (1996).

${ }^{17}$ I. Vickridge and G. Amsel, Nucl. Instrum. Methods Phys. Res. B 45, 6 (1990). 